\title{
PERAN INSENTIF DAN JAMINAN SOSIAL DALAM MENINGKATKAN PRESTASI KERJA KARYAWAN PADA PT. GONDARI MEDIA PRATAMA PADANG
}

\author{
THE ROLE OF INCENTIVE AND SOCIAL GUARANTEE IN IMPROVE \\ EMPLOYEE ACHIEVEMENT OF PT. GONDARI MEDIA PRATAMA PADANG
}

\author{
Lenny Hasan ${ }^{1}$, M. Yusri Syah Putra ${ }^{2}$, Liza Zulbahri ${ }^{3}$ \\ Universitas Tamansiswa Padang ${ }^{1,2,3}$ \\ lenihasan@gmail.com ${ }^{1}$
}

\begin{abstract}
There are several factors that affect employees at work, so that it gives an impact on work performance generated by employees, while the factors in the form of incentives and social security provided by the company. This study aims to determine the effect of incentives and social security on the work performance of employees of PT. Gondari Media Pratama Padang partially or simultaneously. The research method used is quantitative. The sampling technique used is saturated sampling, so the sample is 60 respondents. Data analysis techniques used are multiple linear regression, $t$ test, $F$ test and coefficient of determination. Based on the partial test results found that incentives and social security have a positive and significant effect on the work performance of employees of PT. Gondari Media Pratama Padang because the significant value $<$ alpha $(\alpha)=0.05$. The results of testing together found that incentives and social security have a positive and significant effect on the work performance of PT. Gondari Media Pratama Padang because the significant value $<$ alpha $(\alpha)=0.05$. Based on the test results the coefficient of determination is known as Adjusted R-Square value of 0.480 , meaning that the ability of the incentive variable (X1) and social security (X2) explains work performance by only $48 \%$ while the remaining $52 \%$ is explained by other variables not used in this study.
\end{abstract}

Keywords: Incentives, Social Security and Job Performance.

\begin{abstract}
ABSTRAK
Terdapat beberapa faktor yang mempengaruhi karyawan dalam bekerja, sehingga memberikan dampak terhadap prestasi kerja yang dihasilkan oleh karyawan, adapun faktor tersebut berupa pemberian insentif dan jaminan sosial yang diberikan perusahaan. Penelitian ini bertujuan untuk mengetahui pengaruh insentif dan jaminan sosial terhadap prestasi kerja karyawan PT. Gondari Media Pratama Padang secara parsial maupun simultan. Metode penelitian yang digunakan adalah kuantitatif. Teknik pengambilan sampel yang digunakan adalah sampling jenuh, sehingga sampel 60 responden. Teknik analisis data yang digunakan adalah regresi linear berganda, uji t, uji $\mathrm{F}$ dan koefesien determinasi. Berdasarkan hasil pengujian secara parsial ditemukan insentif dan jaminan sosial berpengaruh secara positif dan signifikan terhadap prestasi kerja karyawan PT. Gondari Media Pratama Padang karena nilai signifikan <alpha $(\alpha)=0,05$. Hasil pengujian secara bersama-sama ditemukan ditemukan insentif dan jaminan sosial berpengaruh secara positif dan signifikan terhadap prestasi kerja karyawan PT. Gondari
\end{abstract}


Media Pratama Padang karena nilai signifikan $<$ alpha $(\alpha)=0,05$. Berdasarkan hasil pengujian koefisien determinasi diketahuinilai Adjusted $R$-Square dengan sebesar 0,480, artinya kemampuan variabel insentif $\left(\mathrm{X}_{1}\right)$, dan jaminan sosial $\left(\mathrm{X}_{2}\right)$ menjelaskan prestasi kerja hanya sebesar $48 \%$ sedangkan sisanya $52 \%$ dijelaskan oleh variabel lain yang tidak digunakan dalam penelitian ini.

Kata Kunci: Insentif, Jaminan Sosial dan Prestasi Kerja.

\section{PENDAHULUAN}

PT. Gondari Media Pratama Sumatera Baratberalamat di Jalan Linggar Jati I Nomor 2 Kota Padang, adalah perusahaan bisnis partnernya PT. Unilever Indonesia, Tbk, yang bergerak dalam bidang activity implementasi, dalam arti perusahaan ini membantu perusahaan PT. Unilever Indonesia, Tbk, dalam bentuk Visibility dan promosi produk-produk PT. Unilever Indonesia, Tbk. Perusahaan ini menjalin kerja sama semenjak tahun 1999 sampai sekarang.

Menurut Sutrisno (2016), prestasi kerja adalah sebagai hasil yang telah dicapai seseorang dari tingkah laku kerjanya dalam melaksanakan aktivitas kerja. Informasi tentang tinggi rendahnya prestasi kerja seorang karyawan tidak dapat diperoleh begitu saja, tetapi diperoleh melalui proses panjang yaitu proses penilaian prestasi kerja karyawan yang disebut dengan istilah performance appraisal.

Terdapat beberapa faktor yang mempengaruhi karyawan dalam bekerja, sehingga memberikan dampak terhadap prestasi kerja yang dihasilkan oleh karyawan, adapun faktor tersebut berupa pemberian insentif dan jaminan sosial yang diberikan perusahaan.

$$
\text { Menurut Rivai dalam }
$$

Kadarisman (2014), insentif merupakan sebagai bentuk pembayaran yang dikaitkan dengan kinerja dan gainsharing, sebagai pembagian keuntungan bagi karyawan akibat peningkatan produktivitas atau penghematan biaya. Penelitian Prasetyo
(2015) dan Kastalani (2015), menemukan pemberian insentif berpengaruh signifikan terhadap peningkatan prestasi kerja karyawan.

Pemberian insentif pada sebagian besar karyawan PT. Gondari Media Pratama Padang tidak pernah mendapatkan insentif, karena karyawan tersebut tidak termotivasi dalam pencapain target yang ditetapkan karena insentif yang diberikan perusahaan masih tergolong kecil, permasalahan ini biasa terjadi pada karyawan bagian bawah seperti Sales dengan tidak tercapainya target pada karyawan bagian bawah maka berdampak pada pimpinannya. Permasalahan ini menandakan bahwa prestasi kerja yang dimiliki oleh karyawan tersebut masih rendah.

Pemeliharaan kesehatan dimaksudkan untuk meningkatkan produktivitas pekerja sehingga dapat melaksanakan tugas sebaik-baiknya dan merupakan upaya kesehatan di bidang penyembuhan. Penelitian oleh Rafica (2017), menjelaskan jaminan sosial mempunyai hubungan yang signifikan dengan prestasi kerja karyawan.

PT. Gondari Media Pratama memberikan 3 (tiga) jenis jaminan sosial untuk karyawan seperti BPJS Ketenagakerjaan, jaminan sosial ini diberikan khusus untuk karyawan perusahaan saja hal ini berlaku apabila terjadi kecelakaan, maka karyawan dapat mempergunakan fisilitas tersebut dengan mendatangi rumah sakit terdekat yang sudah melakukan kerja sama dengan pihak BPJS Ketenagakerjaan. 
BPJS Kesehatan dapat dipergunakan oleh karyawan maupun keluarga karyawan dalam rangka pemeriksaan kesehatan dengan mendatangi rumah sakit terdekat yang sudah melakukan kerja sama dengan pihak BPJS Kesehatan. Sedangkan jaminan sosial dalam bentuk santunan yang diberikan oleh PT. Gondari Media Pratama yaitu nilai atau nominal yang bervariasi seperti sakit Rp. 250.000, meninggal dunia Rp. 1.500.000, melahirkan Rp. 500.000 dan menikah Rp. 500.000. Tetapi dalam pemberian jaminan sosial tersebut membuat karyawan merasa kecewa karena pada saat karyawan menggunakan fasilitas tersebut biaya-biaya rumah sakit di tanggulangi oleh karyawan terlebih dahulu, namun pada saat melakukan klaim biaya tersebut membutuhkan waktu yang cukup lama karena harus diverikasi terlebih dahulu oleh pihak BPJS.

Permasalahan yang terjadi di atas maka akan berdampak pada prestasi kerja PT. Gondari Media Pratama Padang. Prestasi kerja karyawan PT. Gondari Media Pratama Padang masih belum sesuai dengan keinginan perusahaan karena masih terdapat karyawan yang tidak mencapai target dalam bekerja permasalah ini disebabkan karena tingkat pendidikan yang dimiliki karyawan masih terbilang rendah karena pada umumnya tamatan SLTA sederajat, selain itu masa kerja yang dimiliki karyawanpun masih terbilang baru karena pada umumnya masa kerja karyawan tersebut berkisar antara 2-3 tahun. Karyawan PT. Gondari Media Pratama Padang memiliki masa kerja paling lama 3 tahun, setelah masa kerja mencapai 3 tahun maka karyawan tersebut akan dilakukan pemutusan hubungan kontrak kerja dan dilakukan kontrak kerja baru apabila karyawan tersebut masih berkeinginan untuk bekerja pada perusahaan tersebut. Prestasi kerja karyaan tidak dapat dinilai/diukur secara terus menerus (continue) karena terbatasnya masa kerja karyawan sehingga karyawan yang berprestasi tidak dapat menunjukkan prestasi kerjanya secara maksimal.

Permasalahan insentif dan jaminan sosial yang diterima oleh karyawan PT. Gondari Media Pratama Padang akan berdampak pada prestasi kerja karyawan, karena dengan pemberian insentif yang kurang efektif maka karyawan tersebut tidak terdorong untuk melakukan pekerjaan yang lebih baik sehingga target yang diberikan kepadanya belum terealisasi dengan baik. Selain itu jaminan sosial yang diberikan kepada karyawan tidak berjalan sesuai dengan ketentuan yang telah ditentukan maka sebagian besar karyawan tersebut tidak mempedulikan fasilitas jaminan sosial tersebut, karena terdapat kepengurusan yang sulit ketika mempergunakan jaminan sosial tersebut terutama pada jaminan kesehatan. Kejadian tersebut membuat karyawan kecewa sehingga karyawan kurang puas dengan jaminan sosial yang diberikan oleh perusahaan, dan dorongan karyawan untuk melakukan pekerjaan lebih baik cenderung menurun. Berbagai permasalah yang terjadi pada karyawan PT. Gondari Media Pratama Padang seperti pemberian insentif dan jaminan sosial memberikan pengaruh terhadap prestasi kerja yang dihasilkan oleh karyawan.

\section{METODE PENELITIAN \\ Populasi dan Sampel}

Populasi penelitian ini adalah karyawan pada PT. Gondari Media Pratama area Padang dengan jumlah 60 orang karyawan.Teknik pengambilan sampel digunakan dalam penelitian ini adalah sampling jenuh, yaitu teknik 
penentuan sampel bila semua anggota populasi digunakan sebagai sampel.Berdasarkan penjelasan tersebut maka sampel yang digunakan dalam penelitian ini adalah sebanyak 60 orang karyawan.

Jenis data yang digunakan dalam penelitian ini adalah data kualitatif dan data kuantitatif. Sedangkan sumber data yang digunakan adalah sumber primer dan sumber sekunder. Teknik pengumpulan yang digunakan dalam penelitian ini adalah observasi, studi kepustakaan, dan angket. Teknik analisa data yang digunakan dalam penelitian ini adalah statistik deskriptif, uji validitas, uji reliabilitas, uji regresi linear berganda, uji t, uji $\mathrm{F}$ dan uji koefisien determinasi.

\section{HASIL DAN PEMBAHASAN Uji F (Uji Model)}

Berdasarkan hasil pengujian secara simultan dengan judul pengaruh insentif dan jaminan sosial terhadap prestasi kerja karyawan pada PT.Gondari Media Pratama Padang, maka diketahui hasil sebagai berikut:

Tabel 1Hasil Uji F (Simultan)

\begin{tabular}{|c|c|c|c|c|c|c|}
\hline & & & NO & & & \\
\hline & odel & Sum of & $\mathrm{df}$ & Mean & $\mathrm{F}$ & Sig. \\
\hline & $\begin{array}{l}\text { Regressio } \\
\mathrm{n}\end{array}$ & $\begin{array}{r}2159,79 \\
8 \\
\end{array}$ & 2 & $\begin{array}{r}1079,89 \\
9 \\
\end{array}$ & 28,208 &, $000^{\mathrm{b}}$ \\
\hline 1 & Residual & $\begin{array}{r}2182,13 \\
6 \\
\end{array}$ & 57 & 38,283 & & \\
\hline & Total & $\begin{array}{r}4341,93 \\
3\end{array}$ & 59 & & & \\
\hline
\end{tabular}

a. Dependent Variable: Prestasi_Kerja

b. Predictors: (Constant), Jaminan Sosial, Insentif Sumber : Data Olahan (2020)

Berdasarkan Tabel 1, diketahui variabel variabel insentif $\left(\mathrm{X}_{1}\right)$ dan jaminan sosial $\left(\mathrm{X}_{2}\right)$ secara bersamaan berpengaruh signifikan terhadap prestasi kerja karyawan pada PT.Gondari Media Pratama Padang, karena memiliki nilai $F$ hitung sebesar 28,208dengan nilai $\mathrm{F}_{\text {tabel }} d f_{1}=\mathrm{k}-1(3-$ $1=2), \quad d f_{2}=\mathrm{n}-\mathrm{k} \quad(60-3=57) \quad$ adalah 3,16sehingga nilai $F_{\text {hitung }}(28,208)>$ $\mathrm{F}_{\text {tabel }}(3,16)$ dan tingkat signifikan $0,000<$ 0,05 maka jaminan sosial dan insentif secara bersama memiliki pengaruh terhadap prestasi kerja karyawan.

\section{Uji Koefisien Determinasi $\left(\mathbf{R}^{\mathbf{2}}\right)$}

Berdasarkan hasil uji koefisien determinasi pada pengaruh insentif dan jaminan sosial terhadap prestasi kerja karyawan pada PT.Gondari Media Pratama Padang, maka diketahui hasil sebagai berikut:

Tabel 2 Hasil Uji Koefisien Determinasi $\left(\mathbf{R}^{2}\right)$

\begin{tabular}{|c|c|c|c|c|}
\hline \multicolumn{5}{|c|}{ Model Summary } \\
\hline Model & $\mathrm{R}$ & $\begin{array}{c}\mathrm{R} \\
\text { Square }\end{array}$ & $\begin{array}{c}\text { Adjusted } \\
\text { R } \\
\text { Square }\end{array}$ & $\begin{array}{l}\text { Std. Error of } \\
\text { the Estimate }\end{array}$ \\
\hline 1 &, $705^{\mathrm{a}}$ &, 49 & ,480 & 6,18 \\
\hline
\end{tabular}

a. Predictors: (Constant), Jaminan_Sosial, Insentif Sumber : Data Olahan (2020)

Berdasarkan Tabel 2, diketahui bahwa nilai Adjusted R-Square dengan sebesar 0,480, artinya kemampuan variabel insentif $\left(\mathrm{X}_{1}\right)$, dan jaminan sosial $\left(\mathrm{X}_{2}\right)$ menjelaskan prestasi kerja hanya sebesar $48 \%$ sedangkan sisanya $52 \%$ dijelaskan oleh variabel lain yang tidak digunakan dalam penelitian ini seperti Usaha (effort), Abbilities, dan Role/task perception (Sutrisno, 2016).

\section{Hasil Analisis Regresi Linear Berganda}

Analisis ini digunakan untuk mengetahui pengaruh insentif dan jaminan sosial terhadap prestasi kerja. Hasil pengolahan data dibantu dengan komputer melalui program SPSS versi 20.0, maka didapatkan persamaan regresi sebagai berikut: 
Tabel 3 Hasil Uji Regresi Linear Berganda

\begin{tabular}{lcrr}
\hline & \multicolumn{3}{c}{ Coefficients $^{\mathbf{a}}$} \\
\hline & $\begin{array}{c}\text { Unstandardized } \\
\text { Coefficients }\end{array}$ & $\begin{array}{c}\text { Standardize } \\
\text { d } \\
\text { Coefficients }\end{array}$ \\
\cline { 2 - 4 } & $\mathrm{B}$ & Std. Error & Beta \\
\hline (Constant) & 14,550 & 8,706 & \\
\hline Insentif &, 564 &, 159 &, 420 \\
\hline Jaminan Sosial &, 537 &, 174 &, 366 \\
\hline a. Dependent Variable: Prestasi_Kerja & \\
\hline Sumber : Data Olahan (2020) &
\end{tabular}

Uji Hipotesis

Uji t (Parsial)

Berdasarkan hasil pengujian sercara parsial dengan judul pengaruh insentif dan jaminan sosial terhadap prestasi kerja karyawan pada PT.Gondari Media Pratama Padang, maka diketahui hasil sebagai berikut:

Tabel 4 Hasil Uji t (Parsial)

\section{Berdasarkan analisis data dengan menggunakan program SPSS 20, maka diperoleh hasil persamaan regresi sebagai berikut:}

$$
Y=14,550+0,564 X_{1}+0,537 X_{2}+e
$$

1. Dari persamaan regresi variabel di atas dapat diketahui konstanta yang diperoleh sebesar 14,550. Hal ini berarti bahwa, tanpa insentif dan jaminan sosial maka prestasi kerja karyawan PT.Gondari Media Pratama Padang sudah ada sebesar14,550 satuan.

2. Koefisien regresi variabel insentif $\left(\mathrm{X}_{1}\right)$, sebesar 0,564. Artinya jika variabel bebas lainnya tetap dan insentif mengalami kenaikan sebesar satu satuan maka prestasi kerja karyawan PT.Gondari Media Pratama Padang mengalami peningkatan sebesar 0,564 satuan atau $56,4 \%$.

3. Koefisien regresi variabel jaminan sosial $\left(\mathrm{X}_{2}\right)$, sebesar 0,537. Artinya jika variabel bebas lainnya tetap dan jaminan sosial mengalami kenaikan sebesar satu satuan maka prestasi kerja karyawan PT.Gondari Media Pratama Padangmengalami peningkatan sebesar 0,537 satuan atau $53,7 \%$.

\begin{tabular}{ccccccc}
\hline No & Variabel & $\begin{array}{c}\mathbf{t} \\
\text { hitung }\end{array}$ & t tabel & $\begin{array}{c}\text { Nilai } \\
\text { Signifi } \\
\text { kansi }\end{array}$ & $\begin{array}{c}\text { Alph } \\
\mathbf{a ( \alpha )}\end{array}$ & $\begin{array}{c}\text { Ketera } \\
\text { ngan }\end{array}$ \\
\hline 1. & Insentif & 3,553 & 1,671 & 0,001 & 0,05 & $\mathrm{Sig}$ \\
\hline 2. & $\begin{array}{l}\text { Jaminan } \\
\text { Sosial }\end{array}$ & 3,090 & 1,671 & 0,003 & 0,05 & $\mathrm{Sig}$ \\
\hline \multicolumn{7}{l}{ Sumber : Data Olahan (2020) } \\
\end{tabular}

\section{Variabel insentif $\left(\mathrm{X}_{1}\right)$} berpengaruh secara positif dan signifikan terhadap prestasi kerja karyawan pada PT.Gondari Media Pratama Padangdengan nilai signifikan $0,001<0,05$. Hal ini dapat juga dilihat dari nilai $t_{\text {hitung }}>t_{\text {tabel }}$ dengan $\mathrm{df}=\mathrm{n}-$ $\mathrm{k}=60-3=57 \quad(1,672), \quad$ jadi nilai $t_{\text {hitung }}>t_{\text {tabel }}(3,553>1,672)$ maka Ho ditolak dan $\mathrm{H}_{1}$ diterima. Penelitian ini memiliki kesamaan dengan hasil penelitian Prasetyo (2015), yaitu pemberian insentif berpengaruh signifikan terhadap peningkatan prestasi kerja karyawan.

Variabel jaminan sosial $\left(\mathrm{X}_{2}\right)$ berpengaruh secara positif dan signifikan terhadap prestasi kerja karyawan pada PT.Gondari Media Pratama Padangdengan nilai signifikan $0,003<0,05$. Hal ini dapat juga dilihat dari nilai $t_{\text {hitung }}>t_{\text {tabel }}$ dengan $d f=n-$ $\mathrm{k}=60-3=57 \quad(1,672), \quad$ jadi nilai $t_{\text {hitung }}>t_{\text {tabel }}(3,090>1,672)$ maka Ho ditolak dan $\mathrm{H}_{2}$ diterima. Penelitian ini memiliki kesamaan dengan hasil penelitian Rafica (2017), yaitu jaminan sosial mempunyai hubungan yang 
signifikan dengan prestasi kerja karyawan.

Berdasarkan hasil penelitian yang telah dibahas di atas, maka dapat disimpulkan bahwa insentif berpengaruh secara positif dan signifikan terhadap prestasi kerja karyawan pada PT.Gondari Media Pratama Padang. Dalam proses pencapaian tujuan PT.Gondari Media Pratama Padang, karyawan mempunyai peran yang sangat penting sebagai pelaksana kegiatan operasional yang telah ditetapkan oleh perusahaan.

Untuk itu perusahaan harus memperhatikan kebutuhan hidup karyawan dengan baik, salah satunya dengan pemberian insentif seperti pencapaian target penjualan, maka dengan adanya pemberian insentif tersebut dapat memotivasi karyawan untuk bekerja lebih baik lagi. Insentif yang diberikan PT.Gondari Media Pratama Padang kepada karyawannya sesuai dengan jabatan masing-masing hal ini menyakut dengan tanggung jawab yang diberikan kepadanya, semakin banyak tanggung jawab seorang karyawan maka semakin besar insentif yang mereka dapatkan, sehingga semakin baik pula prestasi kerja yang dicapai oleh karyawan PT.Gondari Media Pratama Padang.

Insentif dapat diartikan sebagai balas jasa kepada karyawan yang kinerjanya melebihi standar yang telah ditetapkan oleh PT.Gondari Media Pratama Padang, sehingga insentif tersebut merupakan suatu faktor pendorong bagi karyawan untuk bekerja lebih baik lagi, dimana dengan pemberian insentif diharapkan dapat memotivasi karyawan agar bekerja semaksimal mungkin sehingga tujuan perusahaan dapat tercapai (Purwati \& Satria 2018).

Penelitian ini sejalan dengan penelitian Prasetyo (2015), menemukan pemberian insentif berpengaruh signifikan terhadap peningkatan prestasi kerja karyawan. Namun pemberian insentif pada karyawan berada pada kategori netral, artinya penerapan insentif ini dirasakan oleh karyawan belum cukup memuaskan secara maksimal sehingga penting diperhatikan dengan lebih baik lagi oleh perusahaan agar karyawan dapat bekerja dengan lebih giat dan antusias guna mencapai hasil yang optimal.

\section{Pengaruh Jaminan Sosial terhadap Prestasi Kerja Karyawan}

Berdasarkan hasil penelitian ditemukan jaminan sosial berpengaruh secara positif dan signifikan terhadap prestasi kerja karyawan PT. Gondari Media Pratama Padang. Jaminan sosial yang diberikan PT. Gondari Media Pratama Padang kepada karyawan baik untuk sekarang atau masa yang akan datang, jaminan sosial tersebut dimaksudkan untuk meningkatkan pengabdian dan semangat kerja.

Apabila jaminan sosial mencukupi maka akan dapat menimbulkan kesenangan bekerja sehingga mendorong pemanfaatan kemampuan yang dimilikinya untuk meningkatkan prestasi kerja karyawan. Pegawai yang diberi jaminan sosial akan merasa tenang dalam bekerja, karena mereka merasa telah dilindungi oleh perusahaan bentuk jaminan sosial yang diberikan PT. Gondari Media Pratama Padang dapat berupa BPJS Ketenagakerjaan, BPJS Kesehatan dan Santunan.

BPJS Ketenagakerjaan hanya dapat digunakan oleh karyawan secara individu, sedangkan BPJS kesehatan dapat digunakan oleh karyawan dan keluarga (Anak dan Istri) dan santunan yang diberikan oleh perusahaan ketika sakit, meninggal dunia, melahirkan dan menikah. Maka dengan adanya jaminan 
sosial tersebut membuat karyawan merasa tenang dalam bekerja dan kebutuhan mereka terhadap pelayanan kesehatan akan terpenuhi, fasilitas tersebut tentunya dapat mendorong prestasi kerja karyawan ke arah yang lebih baik lagi.

Penelitian Rafica (2017), menjelaskan jaminan sosial mempunyai hubungan yang signifikan dengan prestasi kerja karyawan. Jadi dengan adanya jaminan sosial tersebut karyawan lebih termotivasi dalam bekerja/berprestasi, apabila karyawan di dalam bekerja hidupnya terjamin/dijamin oleh perusahaan seperti jaminan tenaga kerja, pelayanankesehatan, dan program bantuan karyawan.

\section{Pengaruh Insentif dan Jaminan Sosial terhadap Prestasi Kerja}

Berdasarkan hasil penelitian, terbukti secara bersama insentif dan jaminan sosial berpengaruh secara positif dan signifikan terhadap prestasi kerja karyawan PT. Gondari Media Pratama Padang, hal ini terjadi karena perusahaan memberikan insentif dan jaminan sosial kepada karyawan, sehingga karyawan tersebut memiliki motivasi dalam melaksanakan tanggung jawabnya supaya target yang ditetapkan perusahaan dapat tercapai.

Prestasi kerja karyawan tersebut meningkat dibuktikan dengan karyawan selalu mengerjakan tugas sesuai dengan perintah atasan dan tepat waktu dalam melaksanakannya selain itu karyawan selalu bersosialisasi dengan rekan kerja untuk menyelesaikan pekerjaan yang lebih baik. Tindakan-tindakan yang dilakukan oleh karyawan, maka karyawan tersebut telah menggambarkan sikap yang positif terhadap tanggung jawab yang diberikan kepadanya, sehingga karyawan berusaha mengerjakan tanggung jawab tersebut dengan baik.

Menurut Hasibuan (2014), prestasi kerja adalah suatu hasil kerja yang dicapai seseorang dalam melaksanakan tugas-tugas yang didasarkan atas kecakapan, usaha dan kesempatan. Prestasi kerja merupakan gabungan dari tiga faktor penting yaitu kecakapan, usaha dan kesempatan. Jika ketiga faktor tersebut semakin baik maka prestasi kerja akan semakin baik.

\section{PENUTUP \\ Kesimpulan}

Berdasarkan hasil penelitian yang penulis lakukan, maka kesimpulan dari hasil penelitian tersebut adalah sebagai berikut:

1. Hasil dari analisis regresi linear berganda yaitu variabel insentif $\left(\mathrm{X}_{1}\right)$ dan jaminan sosial $\left(\mathrm{X}_{2}\right)$ berpengaruh pistif dan signifikan terhadap prestasi kerja karyawan PT. Gondari Media Pratama Padang, hal ini dapat dilihat dari persamaan $\mathrm{Y}=14,550+0,564$ $\mathrm{X}_{1}+0,537 \mathrm{X}_{2}$.

2. Hasil uji t pada variabelinsentif $\left(X_{1}\right)$ berpengaruh secara positif dan signifikan terhadap prestasi kerja karyawan PT. Gondari Media Pratama Padang, hal ini dibuktikan dengan nilai $t_{\text {hitung }}>t_{\text {tabel }}(3,553>$ 1,672 ).

3. Hasil uji t pada variabel jaminan $\operatorname{sosial}\left(\mathrm{X}_{2}\right)$ berpengaruh secara positif dan signifikan terhadap prestasi kerja karyawan PT. Gondari Media Pratama Padang, hal ini dibuktikan dengan nilai $t_{\text {hitung }}>t_{\text {tabel }}(3,090>$ 1,672).

4. Hasil uji $F$ pada variabel insentif $\left(\mathrm{X}_{1}\right)$ dan jaminan sosial $\left(\mathrm{X}_{2}\right)$ secara bersamaan berpengaruh signifikan terhadap prestasi kerja karyawan PT. Gondari Media Pratama Padang, hal 
ini dibuktikan dengan nilai $\mathrm{F}_{\text {hitung }}$ $(28,208)>F_{\text {tabel }}(3,16)$.

5. Hasil uji koefisien determinasi didapatkan nilai Adjusted $R$-Square dengan sebesar 0,480, artinya kemampuan variabel insentif $\left(\mathrm{X}_{1}\right)$, dan jaminan sosial $\left(\mathrm{X}_{2}\right)$ menjelaskan prestasi kerja hanya sebesar $48 \%$ sedangkan sisanya $52 \%$ dijelaskan oleh variabel lain yang tidak digunakan dalam penelitian ini seperti Usaha (effort), Abbilities, dan Role/task perception (Sutrisno, 2016).

\section{Saran}

Berdasarkan kesimpulan di atas maka penulis mencoba untuk memberikan saran sebagai berikut:

1. Dari hasil analisis regresi, perusahaan hendaknya dapat mempertahankan pemberian insentif dan jaminan sosial, karena kedua variabel tersebut memiliki pengaruh sama besar terhadap prestasi kerja karyawan.

2. Dari hasil uji t, pada variabel insentif yang perlu dipertimbangkan oleh perusahaan adalah meningkatkan semangat kerja karyawan dengan cara pemberian pelatihan berkomunikasi yang baik, supaya konsumen bisa tertarik untuk membeli produk yang mereka jual.

3. Dari hasil uji t, pada variabel jaminan sosial yang perlu dipertimbangkan oleh perusahaan adalah komitmen mensejahterakan karyawan melalui jaminan sosial yang diberikan, tanpa mempersulit atau pernyaratan yang memberatkan karyawan, supaya karyawan dapat memegang teguh komitmen yang dimiliki perusahaan, sehingga kesejahteraan karyawan lebih meningkat dan prestasi kerja juga lebih meningkat.
4. Dari hasil uji F, pada variabel insentif dan jaminan sosial dapat mempengaruhi prestasi kerja karyawan, maka oleh sebab itu perusahaan harus mempertahankan kedua variabel tersebut, selain itu dapat juga melakukan evaluasi dengan memberikan tambahan insentif seperti memberikan paket liburan, hadiah sepeda motor sedangkan untuk jaminan sosial dapat juga diberikan dengan jaminan hari tua dan santunan lainnya yang bersifat sosial.

5. Dari hasil uji koefisien determinasi, terdapatnya faktor lain seperti usaha, kemampuan karyawan dan juga persepsi risiko yang akan dihadapi oleh karyawan dalam menjalankan pekerjaannya. Maka oleh sebab itu faktor tersebut perlu dikembangkan dengan baik oleh perusahaan, supaya mereka lebih termotivasi untuk bekerja lebih baik lagi, sehingga tujuan yang diinginkan perusahaan dapat tercapai dengan baik.

\section{DAFTAR PUSTAKA}

Hasibuan, M. (2014). Organisasi dan Motivasi Dasar Peningkatan Produktivitas. Cetakan Kedelapan. Jakarta: Bumi Aksara.

Kadarisman. (2014). Manajemen Kompensasi. Cetakan Kedua. Jakarta: Rajagrafindo Persada.

Kastalani, M. (2015). Pengaruh Insentif Terhadap Prestasi Kerja Di Badan Penanggulangan Bencana Daerah Kota Samarinda. Jurnal Fakultas Ilmu Sosial Dan Ilmu Politik, Universitas Mulawarman.

Prasetyo, T. (2015). Pengaruh Insentif Terhadap Prestasi Kerja (Studi Pada Karyawan Bagian Penjualan Dealer Sepeda Motor Merek Honda PT. Mitra 
Pinasthika Mustika Motor

Pekanbaru). Program Studi

Administrasi Bisnis FISIP

Universitas Riau. Jom FISIP

2(2).

Purwati, A., \& Satria, H. (2018). Pengaruh Perekrutan, Motivasi, Dan Pelatihan Terhadap Kinerja Karyawan Pada CV. Skala Sport Pekanbaru. PROCURATIO (Jurnal Ilmiah Manajemen), 5 (4), 418-429.

Rafica, Vivia, \& Maya. (2017). Analisis Pemberian Tunjangan Sosial (Direct Reward) Terhadap Prestasi Kerja Seluruh Karyawan Jawa Timur Park, Malang. Stmik Asia Malang Jibeka, 11(2).

Sutrisno, E. (2016). Manjemen Sumber Daya Manusia. Cetakan Kedelapan. Jakarta: Kencana Prenadamedia Group. 